\title{
HOW FAST DO OLD MEN SLOW DOWN?
}

\author{
Ray C. Fair*
}

Abstract-An important question in the study of aging concerns the rate at which people physically deteriorate with age. How much, for example, can be physically expected of, say, a healthy, non-injured 75 -year-old man or woman relative to what he or she could do at age 45? This paper applies econometric techniques to data on men's track and field and road racing records by age to estimate the rate at which men slow down with age. Eight track, eight fieid, and eleven road racing events are considered. The main econometric technique used is a combination of the polynomial-spline method and the frontier-function method. $A$ number of the events have been pooled to provide more efficient estimates.

\section{Introduction}

$A$ $\mathrm{N}$ important question in the study of aging concerns the rate at which people physically deteriorate with age. How much, for example, can be physically expected of, say, a healthy, non-injured 75-year-old man or women relative to what he or she could do at age 45 ? Policies on aging should obviously depend on the rate at which deterioration occurs. If, for example, the rate remains small into fairly old age, then policies designed to keep people physically fit will have more payoff than if the rate increases rapidly with age. The size of the rate is also relevant for retirement policies. The smaller the rate, the less emphasis should probably be placed on plans to have people retire earlier than they would otherwise want to. The size of the rate may also be relevant for the question of how wage rates should change with age.

This paper applies econometric techniques to data on men's track and field and road racing records by age to estimate the rate at which men slow down with age. Eight track, eight field, and eleven road racing events are considered. The track events range from 100 meters to 10,000 meters, and the road racing events range from

Received for publication December 23, 1991. Revision accepted for publication October 5, 1993.

* Yale University.

I am indebted to Don Andrews, William Brainard, Gregory Chow, Stephen Goldfeld, Ethan Nadel, and Christopher Sims for helpful comments and to Alvin Klevorick for pointing out an error in the data. I am also indebted to Peter Mundle for helpful discussions about the track data and to Basil and Linda Honikman at TACSTATS for supplying me with the road racing data and answering various questions about the data. I would also like to thank the referees for many helpful suggestions.
5 kilometers to the marathon. The field events are the high jump, pole vault, long jump, triple jump, shot put (16 pounds), discus throw ( 2 kilograms), hammer throw (16 pounds), and javelin throw ( 800 grams). The main econometric technique used is a combination of the polynomialspline method and the frontier-function method.

Sections II $-V$ consider the track and road racing events. Section 11 discusses the methodology that was followed, and section III presents the estimation results. Section IV compares the agefactors published in Masters Age-Graded Tables (MAGT) with the age-factors implied by this study. It will be seen that the MAGT age-factors seem to be excessively variable and to be biased against older runners. Table 3 presents the agefactors implied by this study. Section $V$ provides a brief comparison of the present results to results in the physiological literature. Section VI presents the results for the field events, and table 5 presents the age-factors for the field events implied by this study.

\section{The Methodology}

\section{Assumptions}

For a given track or road racing event, let $q_{k}$ denote the log of the time of a runner of age $k$ in the race. For all runners of a given age, the theoretical frequency distribution for $q_{k}$ probably looks something like that depicted in figure 1 . The lower bound, $b_{k}$, is the fastest time that could ever be run by a runner of age $k$. Think of $b_{k}$ as the biological limit of runners of age $k$, given perfect race conditions (but no tail winds allowed) and the use of the best training methods and equipment possible (but no performance enhancing drugs allowed). The median of the distribution is $m_{k}$, and the upper bound is $u_{k}{ }^{1}$

This paper focuses on $b_{k}$, the lower bound for runners of age $k$. The key assumption of this study is that $b_{k}$ when plotted against $k$ looks like

\footnotetext{
I If runners are included in the population who do not finish the race, then $u_{k}$ might be considered to be infinite. This paper does not use $u_{k}$ in the analysis, and so it does not matter here what is assumed about $u_{k}$.
} 
Figure 1.-Theoretical Freouency Distribution of $q_{k}$ FOR INDIVIDUALS OF AGE $k$

$q_{k}=\log$ of time of individual of age $k$

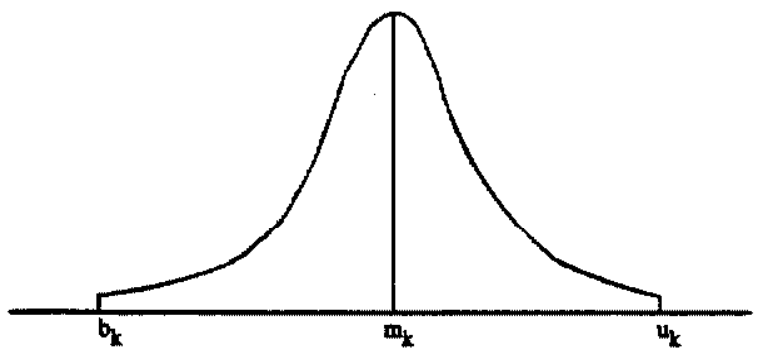

Figure 2.-Assumed Relationship between the Lower BOUND AND AGE

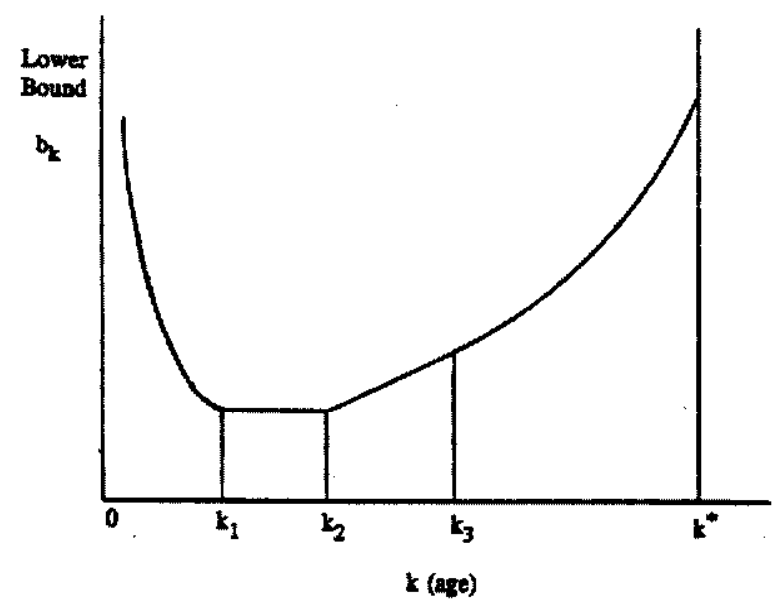

that depicted in figure 2. (Remember that times are measured in logs, so the rates of change are percentage rates of change.) $b_{k}$ is assumed to be infinite for small babies, to fall to some minimum at age $k_{1}$, to stay at this minimum to age $k_{2}$, and then to begin to rise. After $b_{k}$ begins to rise (at $k_{2}$ ), the rate of slowing down is assumed to be constant through age $k_{3}$ and then to begin to rise. $k^{*}$ in the figure is the oldest age at which anyone could finish the race.

The purpose of this paper is to estimate the function in figure 2 from some time after age $k_{2}$ on. The starting age used in the empirical work is 35 , which means that $k_{2}$ is assumed to be less than or equal to $35 . k_{2}$ need not be equal to 35 . If it is less than 35 , this just means that the sample used in this paper picks up the line sometime after $k_{2}$.

The functional form in figure 2 is assumed in the empirical work to be linear between $k_{2}$ and $k_{3}$ and quadratic after that. At $k_{3}$, the linear and quadratic curves are assumed to touch and to have the same first derivative. The specification is

$$
b_{k}= \begin{cases}\alpha_{1}+\alpha_{2} k & \text { for } k_{2} \leq k \leq k_{3} \\ \alpha_{3}+\alpha_{4} k+\alpha_{5} k^{2} & \text { for } k>k_{3},\end{cases}
$$

with the restrictions

$$
\begin{aligned}
& \alpha_{3}=\alpha_{1}+\alpha_{5} k_{3}^{2} \\
& \alpha_{4}=\alpha_{2}-2 \alpha_{5} k_{3} .
\end{aligned}
$$

The two restrictions force the curves to touch and to have the same first derivative at $k_{3}{ }^{2}$ The unrestricted parameters to be estimated are $\alpha_{1}$, $\alpha_{2}, \alpha_{5}$, and $k_{3}$.

It should be stressed that there is no theoretical reason for expecting the curve in figure 2 to be linear between $k_{2}$ and $k_{3}$ and quadratic after that. This study is primarily a curve fitting exercise. After some experimentation, it turned out that the assumption that the curve is linear between $k_{2}$ and $k_{3}$ and quadratic after that seemed to be adequate for fitting the data fairly well. Note that $k_{3}$ is estimated along with the other parameters, and so the data are allowed to decide where the switch from linear to quadratic occurs. If, for example, the curve was in truth quadratic from $k_{2}$ on, the estimate of $k_{3}$ would likely be very close to $k_{2}$ (which, as noted above, is taken to be 35 here).

In the initial experimentation, three other functional forms were tried. First, the quadratic in (1) was replaced with $b_{k}=\alpha_{3}+\alpha_{4} /\left(k-\alpha_{5}\right)$ for $k>k_{3}$. The use of this form did not generally lead to as good fits as did the quadratic, and the curvature seemed too extreme at the top ages. Second, the quadratic was made more general by replacing the exponent 2 with a coefficient $\left(\alpha_{6}\right)$ to be estimated: $b_{k}=\alpha_{3}+\alpha_{4} k+\alpha_{5} k^{\alpha_{6}}$. This allows the curvature to be either more or less extreme than that implied by the quadratic. This did not work because the estimates of $\alpha_{5}$ and $\alpha_{6}$ were too collinear for any confidence to be placed on the results. The estimates of $\alpha_{6}$ were generally around 2 , with large estimated standard errors. Finally, two linear segments were allowed before the quadratic took over, one between $k_{2}$

\footnotetext{
${ }^{2}$ These restrictions are examples of polynomial spline restrictions. See Poirier (1976) for a general discussion of polynomial splines.
} 
and $k_{3}$ and one between $k_{3}$ and, say, $k_{4}$. The two linear segments were restricted to touch at $k_{3}$, and both $k_{3}$ and $k_{4}$ were estimated. This specification did not work for the individual events because the estimates were too collinear, but estimates were obtained for the pooled regression. The results for the pooled regression are reported below. It will be seen that the added generality of two linear segments had only a minor effect on the overall results.

\section{The Data}

The track data are from Masters Age Records for 1990 , and the road racing data are from TACSTATS/USA. The track data give the current world record by age for each event. The road racing data give the current best time by an American for each event. (Data on world records by age are not yet available for road racing.) Let $r_{k}$ denote the log of the observed record time for age $k$ for a given event, and let $\epsilon_{k}$ denote the difference between $r_{k}$ and the unobserved $b_{k} \cdot r_{k}$ can thus be written:

$$
r_{k}=b_{k}+\epsilon_{k} \text {. }
$$

$\epsilon_{k}$ is the measurement error for $r_{k}$.

In principle $\epsilon_{k}$ can be either negative or positive, although negative measurement error does not seem likely. Two possible reasons for negative measurement error are (1) the true distance of the race is shorter than the stated distance, and (2) the time is recorded too low. These kinds of errors are likely to be small because the races and records are monitored closely.

The story is different, however, regarding positive measurement error. The relevant question to consider is how many races for a given event have to be run by runners of age $k$ before $r_{k}$ becomes a good estimate of $b_{k}$ ? Let $N_{k}$ denote the (unobserved) number of men age $k$ who have run the particular event in question up to the current time. If $N_{k}$ is in the millions, as it may be for runners in their $30 \mathrm{~s}$ and $40 \mathrm{~s}$, there is probably a good chance that one has sampled close to the theoretical lower bound. If, on the other hand, $N_{k}$ is only in the thousands or tens of thousands, as it probably is for very old runners, one is not likely to have sampled close to the lower bound. In fact, it is commonly stated that there are now many more runners, say, age 50 than there used to be, and as these runners age, the age records are likely to fall considerably. In 1989 , nine age records in the 100 meters were broken, six of these for ages over 80 . Eleven age records in the 10,000 meters were broken, seven of these for ages over 60 . Results for other events are similar. ${ }^{3}$ The large number of records broken in a single year indicates that the lower bound is far from being observed for many ages. This problem of not having a large enough sample at the higher ages to get a good estimate of the lower bound will be called the "small $N_{k}$ " problem. ${ }^{4}$ Put another way, this problem is simply an order-statistic sampling problem.

Two adjustments were made in the data to try to account for the small $N_{k}$ problem. First, the key assumption of this study is that after age $k_{2}$, $b_{k}$ is greater than $b_{k-i}$ for $i$ positive (men slow down with age). Given this assumption, if $r_{k}$ is greater than $r_{k+i}$ for any positive $i, r_{k}$ must have a relatively large positive measurement error associated with it. Observations of this kind, where the time for a given age is greater than the time for some older age, were not used.

Second, observations at very high ages were not used. The ages not used were always over 78 and in most cases over 81 . The highest age used was 89 , for 100 meters. An age cutoff was made at the point where there was a large increase in the record time from one age to the next relative to the sizes of the previous increases. In discarding observations above the cutoff it is implicitly assumed that the slow times are due to the small $N_{k}$ problem and not to the fact that there is actually a large jump at that age. In other words, the problem is assumed to be a sampling problem, not a biological characteristic.

These two adjustments may not be enough to completely eliminate the small $N_{k}$ problem, and so the following results may be biased in the sense of overestimating the slowdown rate, especially at the older ages. An interesting question

\footnotetext{
${ }^{3}$ Compare the records in Masters Age Records 1990 with those in Masters Age Records 1989.

${ }^{4}$ The reason women were not considered in this study is that the small $N_{k}$ problem seems very serious for them. Societies have not generally encouraged old women to run in track meets and road races.
} 
for future research is whether more can be done with the current data to try to adjust for the small $N_{k}$ problem. It is the case, for example, that $N_{k}$ is likely to be a decreasing function of $k$ and that $\epsilon_{k}$ is a decreasing function of $N_{k}$. Therefore, $\epsilon_{k}$ is likely to be an increasing function of $k$. The approach taken in this study in dealing with this problem is simply to truncate the sample at the point where the size of the effect of $k$ on $\epsilon_{k}$ appears to become large. An alternative approach would be to parameterize the function relating $k$ to $\epsilon_{k}$ (say $\epsilon_{k}=\gamma_{1}+\gamma_{2} k+\gamma_{3} k^{2}$ for $k$ greater than some value $\bar{k}$ ), add this to (3), and try to estimate the new parameters $\left(\gamma_{1}, \gamma_{2}, \gamma_{3}, \bar{k}\right)$ along with the others. The data may not be good enough to allow anything sensible to come out of this, but it is a possible area for further research.

Another possible approach is the following. Denote the density function in figure 1 for a given age $k$ as $f\left(q_{k}, \Theta_{k}\right)$, where $q_{k}$ is the log of the time in the event of an individual of age $k$ and $\Theta_{k}$ is a vector of parameters. Let $q_{k}^{\min }$ denote the minimum value of $q_{k}$ in a sample of size $N_{k} \cdot q_{k}^{\min }$ is an order statistic, and let $g\left(q_{k}^{\min }, \Theta_{k}, N_{k}\right)$ denote its density function. The functional form of $g$ depends, of course, on the functional form of $f$. The data used in this study are observations on $q_{k}^{\min }$ for $k 35$ and over. Given (1) observations on $q_{k}^{\min },(2)$ an assumption about the functional form of $f,(3)$ a parameterization of the elements of $\Theta_{k}$ as functions of $k$, and (4) values for $N_{k}$ or a parameterization of $N_{k}$ as a function of $k$, one could estimate the parameters by maximum likelihood. Again, the data may not be good enough to allow sensible estimates to be obtained using this approach, but it is another possible area for further research.

Until further work is done, the present results should be interpreted with caution. If the same estimation is done ten or twenty years hence, it is likely that the estimated slowdown rates will be smaller than the currently estimated rates. Whether they will be only slightly smaller or a lot smaller is an important open question.

Note finally that if all ages are getting better over time (say because of better nutrition, better training methods, or better equipment), this will not affect the estimated slowdown rates as long as all ages are getting better at the same rate. Progress like this will affect the estimated slow- down rates only if it differentially affects the various ages.

\section{The Econometrics}

Let $d_{k}=1$ if $k \leq k_{3}$ and $d_{k}=0$ if $k>k_{3}$. Using this notation, substituting (1) into (3), and using the restrictions in (2) yields the equation to be estimated:

$$
\begin{aligned}
r_{k}= & \alpha_{1}+\alpha_{2} k+\alpha_{5}\left(1-d_{k}\right) \\
& \times\left(k_{3}^{2}-2 k_{3} k+k^{2}\right)+\epsilon_{k}, \\
& k=35, \ldots, K .
\end{aligned}
$$

There are four parameters to estimate, $\alpha_{1}, \alpha_{2}$, $\alpha_{5}$, and $k_{3}$, where it should be remembered that $d_{k}$ is a function of $k_{3} . K$ is the oldest age in the sample period. There are age gaps in the sample period because of the exclusion of observations with dominated times.

Let $\hat{r}_{k}$ be the predicted value of $r_{k}$ from equation (4) for a particular set of coefficient estimates. The main interest in this study is in the derivative of $\hat{r}_{k}$ with respect to $k$. This derivative is

$$
\partial \hat{r}_{k} / \partial k=\hat{\alpha}_{2}+2 \hat{\alpha}_{5}\left(1-d_{k}\right)\left(k-\hat{k}_{3}\right),
$$

where a hat over a coefficient denotes its estimate. This derivative is not a function of the estimate of the constant term $\alpha_{1}$ in (4), and so the size of the constant term is not of direct concern here.

Equation (4) pertains to a particular event. If one is willing to assume that $\alpha_{2}, \alpha_{5}$, and $k_{3}$ are the same across events, then the data on the different events can be pooled and more efficient estimates obtained. It does not seem unreasonable that the derivatives are the same at least for events close to each other in distance. When the data are pooled, different constant terms are needed for each event, since these obviously vary with distance. When the data were pooled for the results below, the following equation was estimated ( $n$ is the number of events pooled):

$$
\begin{aligned}
r_{i k}=\beta_{1} D_{1 i k}+\cdots+\beta_{n} D_{n i k}+\alpha_{2} k \\
+\alpha_{5}\left(1-d_{i k}\right)\left(k_{3}^{2}-2 k_{3} k+k^{2}\right)+\epsilon_{i k}, \\
\quad i=1, \ldots, n ; k=35, \ldots, K_{i}, \quad(6)
\end{aligned}
$$

where $r_{i k}$ is the log of the observed record for event $i$ and age $k, D_{j i k}$ is a dummy variable that 
is equal to one when event $i$ is equal to $j$ and zero otherwise $(j=1, \ldots, n), d_{i k}=1$ if $k \leq k_{3}$ and $d_{i k}=0$ if $k>k_{3}, \epsilon_{i k}$ is the measurement error for event $i$ and age $k$, and $K_{i}$ is the oldest age used for event $i$. Again, there are age gaps in the sample period for a given event because of the exclusion of dominated observations. The $n$ $\beta_{i}$ coefficients in equation (6) are the $n$ different constant terms.

Return now to the estimation of equation (4). Since positive measurement error for $r_{k}$ is more likely than negative measurement error, the mean of $\epsilon_{k}$ is likely to be positive. If there is no negative measurement error at all, then $\epsilon_{k} \geq 0$ for all $k$. A positive mean for $\epsilon_{k}$ poses no problem in the estimation of equation (4) because the positive mean is merely absorbed in the estimate of the constant term. If the mean of $\epsilon_{k}$ is $\bar{\epsilon}$, define $\epsilon_{k}^{*}=\epsilon_{k}-\bar{\epsilon}$, where $\epsilon_{k}^{*}$ has mean zero. Equation (4) can then be rewritten with $\epsilon_{k}^{*}$ replacing $\epsilon_{k}$ and the constant term changed from $\alpha_{1}$ to $\alpha_{1}+\bar{\epsilon}$. In this case $\alpha_{1}$ is not identified, but this is of no concern here because the derivatives do not depend on $\alpha_{1}$. One can thus estimate (4) by nonlinear least squares in the usual way. This estimation procedure will be called the NLS procedure.

There is, however, another estimation method that is of interest to consider. Under the assumption that $\epsilon_{k} \geq 0$ for all $k$, equation (4) can be estimated under the restriction that all estimated residuals are non-negative. This procedure is common in the estimation of frontier production functions-see, for example, Aigner and Chu (1968) and Schmidt (1976). The one added complication here is that equation (4) is nonlinear in coefficients. For linear equations the estimation problem can be set up as a quadratic programming problem and solved by standard methods, but for nonlinear equations some other procedure must be found.

The procedure used for the results below is the following. In the standard case the coefficients in equation (4) are estimated by minimizing the sum of squared residuals $\sum_{k-35}^{K} \hat{\epsilon}_{k}^{2}$. Instead, one can minimize a weighted sum $\sum_{k=35}^{K} \lambda_{k} \hat{\epsilon}_{k}^{2}$, where $\lambda_{k}$ is equal to 1 if $\hat{\epsilon}_{k} \geq 0$ and is equal to a number greater than one if $\hat{\epsilon}_{k}<0$. This penalizes negative errors more than non-negative ones. For the work below a value of 100 was used for $\lambda_{k}$ when $\hat{\epsilon}_{k}$ was less than zero. This was large enough to make nearly all the estimated residuals non-negative at the optimum. ${ }^{5}$ This estimation procedure will be called the "frontier" procedure.

It turns out, as will be seen below, that the use of the frontier procedure instead of the NLS procedure has only a small effect on the estimated slope coefficients and thus on the estimated derivatives. The use of the frontier procedure primarily affects the estimate of the constant term, which is not of concern here.

An attempt was also made to estimate the parameters of (4) under the assumption that $\epsilon_{k}$ follows a gamma distribution, as discussed in Greene (1980). The use of this distribution has the advantage of allowing the statistical properties of the maximum likelihood estimator to be readily obtained, which the procedure discussed above does not. It also accommodates quite flexible shapes of the error distributions. Unfortunately, sensible results could not be obtained following this approach. The estimates of the two distribution parameters ( $P$ and $\lambda$ in Greene's (1980) notation) were usually not sensible, and convergence was hard to obtain. It would be interesting to see in future work if this approach could be made to work, but the effort so far (which was considerable) was not successful.

\section{Results}

\section{NLS Estimates}

The results of estimating the equation for each event by itself are presented first in table 1 (lines 1-17). The estimates of $\alpha_{2}, k_{3}$, and $\alpha_{5}$ and their estimated standard errors are presented along with the implied values of the derivatives at ages $50,60,75$, and 95 . (The implied value of the derivative for ages below $\hat{k}_{3}$ is $\hat{\alpha}_{2}$.) The estimation technique for these results is NLS.

Set aside for the moment the 100 meter, 200 meter, and marathon events. Of the remaining fourteen events, two stand out as being considerably different from the rest in table 1: 10,000

\footnotetext{
${ }^{3}$ This procedure does not guarantee that all the estimated residuals are non-negative because if $\hat{\epsilon}_{k}$ is negative but very close to zero, its contribution to the objective function is small even if $\lambda_{k}$ is large. In practice the negative errors were very close to zero and were for all intents and purposes zero.
} 
Table 1.-The Estimation Results for the Track and Road Racing Events

\begin{tabular}{|c|c|c|c|c|c|c|c|c|c|c|c|c|c|c|}
\hline \multirow[b]{2}{*}{ Line } & \multirow[b]{2}{*}{ Dist. } & \multirow[b]{2}{*}{$\hat{\boldsymbol{\alpha}}_{2}$} & \multirow[b]{2}{*}{$\operatorname{SE}\left(\hat{\alpha}_{2}\right)$} & \multirow[b]{2}{*}{$\hat{k}_{3}$} & \multirow[b]{2}{*}{$\operatorname{SE}\left(\hat{k}_{3}\right)$} & \multirow[b]{2}{*}{$\hat{a}_{5}$} & \multirow[b]{2}{*}{$\operatorname{SE}\left(\hat{\alpha}_{5}\right)$} & \multicolumn{4}{|c|}{ Derivative at Age } & \multirow[b]{2}{*}{$\mathbf{S E}$} & \multirow{2}{*}{$\begin{array}{l}\text { No. } \\
\text { Obs. }\end{array}$} & \multirow{2}{*}{$\begin{array}{l}\text { Max } \\
\text { Age }\end{array}$} \\
\hline & & & & & & & & 50 & 60 & 75 & 95 & & & \\
\hline & & & & & & & Track & & & & & & & \\
\hline 1 & 100 & .0048 & .0013 & 46.5 & 7.9 & .00013 & .00002 & .0057 & .0083 & .0123 & .0175 & .015 & 29 & 89 \\
\hline 2 & 200 & .0076 & .0003 & 65.8 & 1.8 & .00056 & .00012 & .0076 & .0076 & .0179 & .0403 & .012 & 27 & 82 \\
\hline 3 & 400 & .0068 & .0012 & 51.0 & 5.5 & .00021 & .00004 & .0068 & .0106 & .0168 & .0251 & .016 & 25 & 81 \\
\hline 4 & 800 & .0052 & .0083 & 37.1 & 37.2 & .00012 & .00002 & .0083 & .0107 & .0143 & .0192 & .014 & 28 & 79 \\
\hline 5 & 1500 & .0088 & .0006 & 54.0 & 4.4 & .00018 & .00004 & .0088 & .0109 & .0162 & .0233 & .013 & 31 & 82 \\
\hline 6 & 3000 & .0080 & .0008 & 52.8 & 4.1 & .00024 & .00005 & .0080 & .0114 & .0186 & .0281 & .015 & 24 & 82 \\
\hline 7 & 5000 & .0087 & .0009 & 50.1 & 6.3 & .00013 & .00003 & .0087 & .0112 & .0150 & .0201 & .013 & 29 & 83 \\
\hline 8 & 10000 & .0089 & .0014 & 47.3 & 17.8 & .00006 & .00004 & .0092 & .0105 & .0125 & .0150 & .015 & 24 & 82 \\
\hline \multicolumn{15}{|c|}{ Road Racing } \\
\hline 9 & $5 \mathrm{~K}$ & .0075 & .0012 & 57.6 & 6.2 & .00035 & .00013 & .0075 & .0091 & .0195 & .0335 & .027 & 24 & 82 \\
\hline 10 & $10 \mathrm{~K}$ & .0071 & .0009 & 51.9 & 5.7 & .00020 & .00006 & .0071 & .0104 & .0164 & .0244 & .020 & 31 & 81 \\
\hline 11 & $15 \mathrm{~K}$ & .0066 & .0013 & 48.7 & 7.5 & .00016 & .00004 & .0070 & .0101 & .0147 & .0210 & .016 & 28 & 82 \\
\hline 12 & $10 \mathrm{Ml}$ & .0066 & .0031 & 45.1 & 19.6 & .00011 & .00005 & .0077 & .0100 & .0134 & .0180 & .023 & 20 & 81 \\
\hline 13 & $20 \mathrm{~K}$ & .0052 & .0044 & 42.2 & 21.9 & .00014 & .00005 & .0073 & .0100 & .0141 & .0196 & .025 & 18 & 81 \\
\hline 141 & $1 / 2 \mathrm{MA}$ & .0042 & .0076 & 40.1 & 25.0 & .00018 & .00004 & .0077 & .0113 & .0166 & .0237 & .029 & 22 & 81 \\
\hline 15 & $30 \mathrm{~K}$ & .0054 & .0033 & 46.7 & 13.5 & .00023 & .00012 & .0070 & .0116 & .0185 & .0277 & .032 & 12 & 78 \\
\hline 16 & $20 \mathrm{MI}$ & .0055 & .0024 & 49.1 & 9.4 & .00028 & .00011 & .0059 & .0115 & .0198 & .0309 & .027 & 11 & 78 \\
\hline 17 & MA & .0063 & .0009 & 58.2 & 2.5 & .00061 & .00012 & .0063 & .0085 & .0269 & .0515 & .019 & 21 & 79 \\
\hline \multicolumn{15}{|c|}{ Pooled } \\
\hline $18^{\mathrm{a}}$ & & .0069 & .0006 & 47.7 & 3.0 & .00016 &.$\overline{00001}$ & .0076 & .0109 & .0157 & .0221 & .021 & 256 & 83 \\
\hline $19^{b}$ & & .0057 & .0018 & 49.0 & 7.5 & .00026 & .00009 & .0062 & .0115 & .0194 & .0299 & .030 & 23 & 78 \\
\hline \multicolumn{15}{|c|}{ Frontier Method } \\
\hline & Line $^{c}$ & & & & & & & & & & & & & \\
\hline 20 & 1 & .0046 & - & 49.3 & - & .00014 & - & .0048 & .0077 & .0120 & .0177 & - & 29 & 89 \\
\hline 21 & 2 & .0079 & - & 66.9 & - & .00064 & - & .0079 & .0079 & .0183 & .0441 & - & 27 & 82 \\
\hline 22 & 18 & .0081 & - & 51.4 & - & .00014 & - & .0081 & .0104 & .0146 & .0201 & - & 256 & 83 \\
\hline 23 & 19 & .0045 & - & 51.8 & - & .00035 & - & .0045 & .0103 & .0209 & .0351 & - & 23 & 78 \\
\hline 24 & 17 & .0053 & - & 59.0 & - & .00077 & - & .0053 & .0068 & .0375 & .0606 & - & 21 & 79 \\
\hline
\end{tabular}

Note: Max Age = Oldest age used in the sample period.

The pooled equations are $3-7,10-14$.

the pooled equations are $15,16$.

The frontier method ased for the equation in this line above.

meters and $5 \mathrm{~K}^{6}$ For 10,000 meters there is a small estimate of $\alpha_{5}$, which means that the derivatives grow very slowly with age. For $5 \mathrm{~K}$ the opposite is true. Note in particular that 10,000 meters is quite different from $10 \mathrm{~K}$ even though it is the same distance, and likewise for $5 \mathrm{~K}$ and 5,000 meters. It may be that the 10,000 meter and SK results reflect considerable measurement error, given that they are so different from the rest.

The other two events that have somewhat different results are $30 \mathrm{~K}$ and 20 miles. These both have slightly larger estimates of $\alpha_{5}$ than the events between $\mathbf{4 0 0}$ meters and the half marathon except for $\mathbf{3 0 0 0}$ meters. Two things could be going

\footnotetext{
${ }^{6}$ The 5000 meter and 10000 meter road racing events are denoted $5 \mathrm{~K}$ and $10 \mathrm{~K}$, respectively, to distinguish them from the track events of the same distance.
}

on here. First, it may be that at roughly the $30 \mathrm{~K}$ distance, the slowdown rate at a given age begins to increase, and this is what the estimates are picking up. Second, the results may be unreliable. The $30 \mathrm{~K}$ and 20 mile events are not as popular as the others, and so there is more of a potential small $N_{k}$ problem here. The potential small $N_{k}$ problem also reveals itself in the fact that the samples are small for these two events (12 and 11 observations, respectively). The samples are small because many of the records were dominated by records at older ages and so were discarded. The high number of dominated records probably indicates a small $N_{k}$ problem. It is thus an open question as to whether the $30 \mathrm{~K}$ and 20 mile results are capturing an increase in the slowdown rate at a given age across distances or are simply due to a small sample problem. 
The remaining five track events (400 meters through 5,000 meters) and five road racing events (10K through the half marathon) give similar results. There is no evidence of anything varying in a systematic way across distances. The implied derivatives at age 60 across the ten distances are in remarkably close agreement; the range is only 0.0100 at 10 miles and $20 \mathrm{~K}$ to 0.0114 at 3000 meters. There is more variation in the estimates of $\alpha_{2}$, where the range is 0.0042 at the half marathon to 0.0087 at 5000 meters. The range at age 75 is 0.0134 at 10 miles to 0.0186 at 3000 meters, and the range at age 95 is 0.0180 at 10 miles to 0.0281 at 3000 meters. The estimated standard errors for $\hat{\alpha}_{2}$ and $\hat{k}_{3}$ are fairly large for some events.

Given that no systematic variation across distances is evident in the ten events, it seems sensible to pool them to obtain more efficient estimates. The results of doing this are reported in line 18 in table 1 . The estimate of $\alpha_{2}$ is 0.0069 , with an estimated standard error of 0.0006 , and the estimate of $k_{3}$ is 47.7 , with an estimated standard error of 3.0. The derivatives are 0.0076 at age 50, 0.0109 at age $60,0.0157$ at age 75 , and 0.0221 at age 95 . $^{7}$

These pooling results are not sensitive to the exclusion of the 10,000 meters, $5 \mathrm{~K}, 30 \mathrm{~K}$, and 20 mile events. When the observations from these events are included in the pooling, the estimates of $\alpha_{2}$ and $k_{3}$ are 0.0069 and 48.3 , respectively, and the derivatives at ages $50,60,75$, and 95 are $0.0075,0.0109,0.0159$, and 0.0227 , respectively.

\footnotetext{
TUder the assumption that $\epsilon_{k}$ is normally distributed, which cannot be quite right because of the truncation issues, an $F$-test can be used to test the hypothesis that $\alpha_{2}, \alpha_{5}$, and $k_{3}$ are the same across the ten events. There are 27 restrictions, and the number of observations in the pooled regression is 256 . The $F$-value was 2.17 , which compares with the critical value at the $1 \%$ level of 1.82 , and so the hypothesis is rejected. Similar results were obtained when other sets of events were used. The hypothesis that the coefficients are the same across the specified events was usually rejected, atthough the computed $F$-values were usually not too much above the critical values. (The hypothesis that the coefficients are the same for $30 \mathrm{~K}$ and $\mathbf{2 0}$ miles was, however, not rejected at the $5 \%$ level.)

I am not inclined to take these rejections as strong evidence against pooling. The computed $F$-values were never too far from not rejecting the null hypothesis; the sample size is small relative to the number of restrictions; and there seems to be no compelling reason for believing that the coefficients change across the particular events, especially since no systematic patterns across the ten events were evident when the equations were estimated individually.
}

These estimates are very close to the estimates presented in table 1 when the four events are excluded.

Consider now the 100 meter, 200 meter, $30 \mathrm{~K}$, 20 mile, and marathon events. For 100 meters the results indicate that the rate of slowdown is smaller than it is for the other events. The estimated age at which the quadratic takes over is similar for 100 meters versus the pooled sample ( 46.5 versus 47.7 ), but the sizes of the derivatives are smaller. For example, at age 60 the slowdown rate is 0.0083 compared to 0.0109 for the pooled sample. At age 95 the rate is 0.0175 compared to 0.0221 for the pooled sample.

The results for 200 meters are quite different from the rest. The estimated age at which the quadratic takes over is 65.8 , which is much higher than the other estimates. Also, the estimate of $\alpha_{5}$ is much larger, which means that once the quadratic takes over, the estimated increase in the slowdown rate is larger than it is for the other events. The derivatives at age 60 are similar for 100 and 200 meters, but the derivative is noticeably larger at age 75 for 200 meters and considerably larger at age $95(0.0403$ versus 0.0175$)$. Because the 200 meter results stand out as being much different from the rest-both from the 100 meter results and from the results for $\mathbf{4 0 0}$ meters and above-they should be interpreted with considerable caution. It seems likely, for example, that the increase in the slowdown rate after age 64 has been overestimated.

Given that the results for $30 \mathrm{~K}$ and 20 miles are similar to each other and differ somewhat from the rest, it is of interest to pool the two events. The results of this pooling are presented in line 19 in table 1 . Comparing lines 18 and 19 , it can be seen that the estimated slowdown rate for $30 \mathrm{~K}$ and 20 miles is lower at the younger ages and higher at the older ages. Although not shown in the table, the age at which the slowdown rate becomes greater for $30 \mathrm{~K}$ and 20 miles is about 59 . By age 95 the estimated slowdown rate is 0.0299 for $30 \mathrm{~K}$ and 20 miles versus 0.0221 for the others.

The results for the marathon in line 17 continue the pattern of the estimated slowdown rate being lower at the younger ages and higher at the older ages. Although not shown in the table, the age at which the slowdown rate becomes greater for the marathon compared to the pooled events in line 18 is about 63 . The estimated age at which 
the quadratic takes over is 58.2 , which is higher than all the other estimates except the one for 200 meters. The estimate of $\alpha_{2}$ is 0.0063 , which means that until age 58 the estimated slowdown rate is constant at $0.63 \%$ per year. After age 58 the estimated slowdown rate picks up fairly rapidly (the estimate of $\alpha_{5}$ is large), and by age 95 the derivative is by far the largest of any event at 0.0515 . This derivative is even much larger than the derivative for the $30 \mathrm{~K}$ and 20 mile events.

The differences between the marathon derivatives and the other derivatives at the older ages are large enough to make one question whether the marathon results should be trusted. There may be, however, more to the marathon than a mere 6.2 miles beyond 20 miles. Anyone who has run the last 6.2 miles in a marathon can appreciate this. If there is an important nonlinearity in going from 20 miles to the marathon, one might expect there to be a more rapid increase in the rate of slowing down at older ages for the marathon. This is what the current results show, although the estimated size of the effects should be taken with considerable caution.

\section{Frontier Estimates}

The final estimates in table 1 were obtained using the frontier procedure. Results are presented for 100 meters, 200 meters, pooled 400 meters through the half marathon, pooled $30 \mathrm{~K}$ and 20 miles, and the marathon. The results using the frontier procedure are quite similar to the other results. None of the comparisons and conclusions discussed above are changed by the frontier results, although the results for $\mathbf{2 0 0}$ meters (line 21) are somewhat less extreme using the frontier method than they are using NLS.

\section{Graphs}

Figure 3 presents plots of actual and predicted values for four events -100 meters, 200 meters, 5000 meters, and the marathon. The actual values are the values used in the estimation, and so they do not include the dominated values (which were excluded) and the values excluded at the high ages. The predicted values are from the frontier estimates. For 100 meters, 200 meters, and the marathon, the frontier estimates are presented in lines 20,21 , and 24 , respectively, in table 1 . The frontier estimates for 5000 meters were obtained, but they are not presented in table 1.

The plots for 100 meters and 5000 meters show that the curvature for the quadratic is quite modest once the quadratic takes over. The plot for 5000 meters is quite typical of the events 400 meters through the half marathon. The quadratic

Figure 3a.-Actyal ( $\bullet$ and Predicted (+) Values for 100 Meters

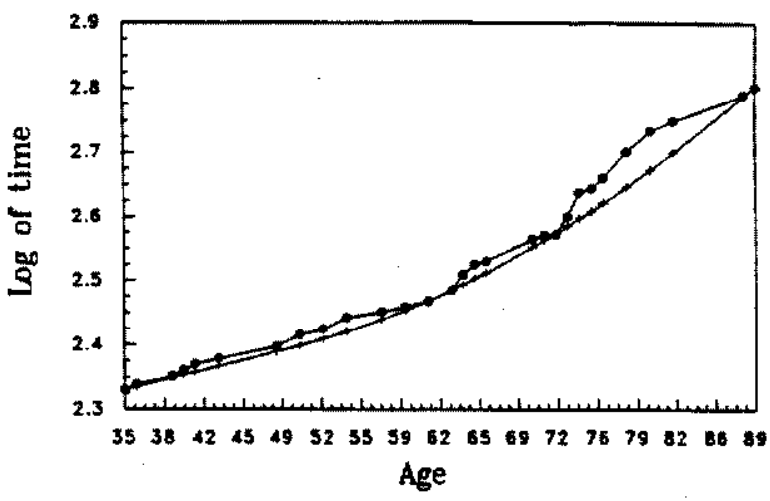

Figure 3b-Actual. ( $\bullet$ and Predicted ( + ) Values for 200 METERS

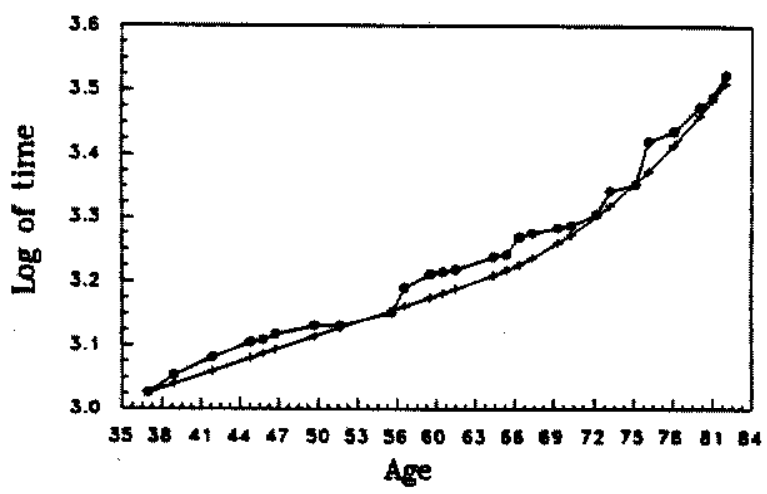

Figure 3c.-Actual (ø) and Predicted ( + ) Values for 5000 Meters

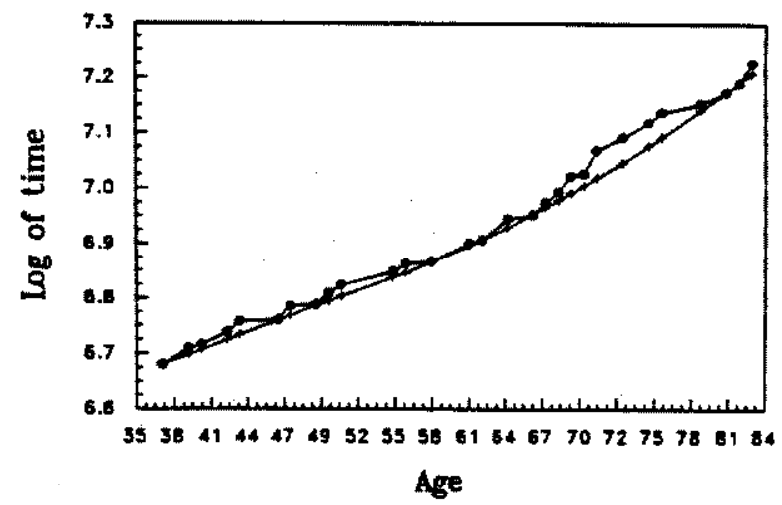


Ficure 3d.-Actual ( $\bullet$ ) and Predicted (+) Values for the MARATHON

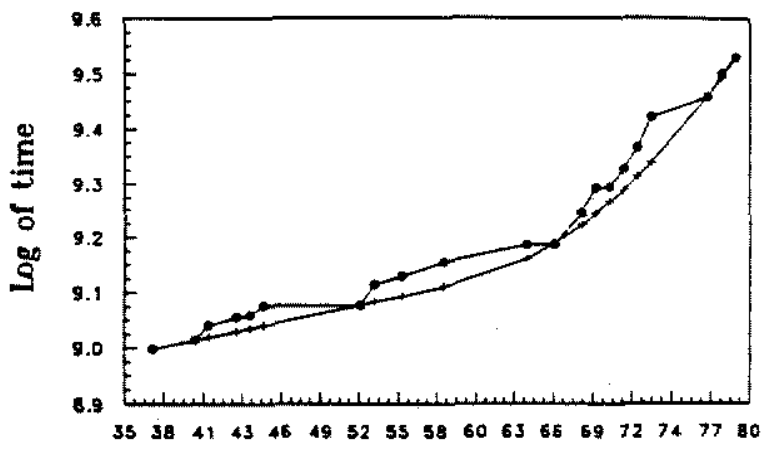

Age

for 200 meters does not begin until age 63 , but after it begins the curvature is greater than that for 100 meters and 5000 meters. This feature was discussed above. The curvature is much greater for the marathon once the quadratic takes over, which was also discussed above. The four plots in figure 3 give a good indication of the nature of the data and the type of fits that were obtained.

\section{Estimating an Additional Linear Segment}

As mentioned in section II, the main pooled equation (line 18 in table 1) was also estimated assuming two linear segments before the quadratic takes over. In this case two additional parameters are estimated, the slope of the second linear segment and the break point between the two linear segments. This added flexibility resulted in a very modest increase in fit - the standard error of the regression only fell from 0.02108 to 0.02063 . The two estimated break points were 40.2 and 48.0, compared to the one break point of 47.7 in line 18. The estimated standard error of the first estimated break point was large, 17.5. The slope of the first linear segment was slightiy larger than the slope of the second linear segment $(0.0088$ versus 0.0082$)$, but the difference was not close to being statistically significant. The derivative at age 60 was 0.0112 compared to 0.0109 in line 18 , and the derivative at age 95 was 0.0198 compared to 0.0221 in line 18 . In short, the added flexibility made little difference.

\section{Age-Graded Tables}

It is possible to use the coefficient estimates in table 1 to estimate the ratio (denoted $R_{k}$ ) of the lower bound time at a given age $k$ to the best lower bound time regardless of age. To do this, one needs a starting point, which in the present case is a value for $R_{35}$. Given $R_{35}, R_{36}$ is $R_{35}(1$ $+D_{36}$ ), where $D_{k}$ is the derivative at age $k$ computed from the estimated equation (remember that the derivatives are in percentage terms). $R_{37}$ is then $R_{36}\left(1+D_{37}\right)$, and so on.

The inverse of $R_{k}$ is called an "age-factor" in Masters Age-Graded Tables (MAGT), and tables of age-factors are presented in MAGT for various events. Although MAGT does not explain how the age-factors were arrived at, it is of interest to see how they compare to the age-factors computed in this study. Table 2 presents the implied values of $R_{k}$ (the inverse of the age-factors) from the table on page 24 in MAGT. These age-factors are for the $5 \mathrm{~K}$ through half marathon events. The percentage changes in $R_{k}$ are also presented in table 2 , along with the change in the percentage changes. These are the equivalent of the first and second derivatives of equation (4).

Table 2 shows that the MAGT value of $R_{k}$ for age 35 is 1.02838 . This means that MAGT has assumed that some loss in time has occurred by age 35 ( $2.838 \%$ to be exact).

Table 2 also presents values of $R_{k}$ implied by the estimates in line 22 in table 1 . These are the estimates for the pooled events 400 meters through the half marathon, estimated by the frontier procedure. To make these values of $R_{k}$ comparable to the MAGT values, the MAGT value of 1.02838 was used for $R_{35}$ for the starting point. The derivatives from the equation and the changes in the derivatives are also presented in table 2.

Two interesting conclusions emerge from table 2. First, the MAGT derivatives are (with one exception) increasing with age, but the sizes of the increases are erratic. The derivatives from this study, on the other hand, are constant through age 47 (actually 47.7 ) and then change at a constant amount $(0.00028)$ after that. This constant rate of change is, of course, due to the use of the quadratic functional form. The erratic behavior of the change in the MAGT derivatives does not seem sensible. It seems unlikely, for example, that the derivative would change by 0.00033 at age $77,0.00003$ at age $78,0.00050$ at age 79 , and 0.00004 at age 80 . Nature is not generally like this. 
Table 2-Comparison of Estimated Age-Factors

\begin{tabular}{|c|c|c|c|c|c|c|}
\hline \multirow[b]{2}{*}{ Age } & \multicolumn{3}{|c|}{ MAGT } & \multicolumn{3}{|c|}{ Present Study } \\
\hline & $R_{k}$ & $D_{k}$ & $D_{k}-D_{k-1}$ & $R_{k}$ & $D_{k}$ & $D_{k}-D_{k-1}$ \\
\hline 35 & 1.02838 & - & - & 1.02838 & - & - \\
\hline 36 & 1.03455 & 0.00600 & - & 1.03666 & 0.00805 & 一 \\
\hline 37 & 1.04080 & 0.00604 & 0.00004 & 1.04501 & 0.00805 & 0.00000 \\
\hline 38 & 1.04723 & 0.00618 & 0.00014 & 1.05343 & 0.00805 & 0.00000 \\
\hline 39 & 1.05374 & 0.00622 & 0.00004 & 1.06191 & 0.00805 & 0.00000 \\
\hline 40 & 1.06045 & 0.00636 & 0.00015 & 1.07047 & 0.00805 & 0.00000 \\
\hline 41 & 1.06724 & 0.00640 & 0.00004 & 1,07909 & 0.00805 & 0.00000 \\
\hline 42 & 1.07411 & 0.00644 & 0.00004 & 1.08778 & 0.00805 & 0.00000 \\
\hline 43 & 1.08120 & 0.00660 & 0.00015 & 1.09654 & 0.00805 & 0.00000 \\
\hline 44 & 1.08849 & 0.00675 & 0.00015 & 1.10537 & 0.00805 & 0.00000 \\
\hline 45 & 1.09589 & 0.00679 & 0.00005 & 1.11428 & 0.00805 & 0.00000 \\
\hline 46 & 1.10327 & 0.00673 & -0.00006 & 1.12325 & 0.00805 & 0.00000 \\
\hline 47 & 1.11086 & 0.00689 & 0.00016 & 1.13230 & 0.00805 & 0.00000 \\
\hline 48 & 1.11882 & 0.00716 & 0.00027 & 1.14142 & 0.00805 & 0.00000 \\
\hline 49 & 1.12714 & 0.00744 & 0.00028 & 1.15061 & 0.00805 & 0.00000 \\
\hline 50 & 1.13585 & 0.00772 & 0.00028 & 1.15988 & 0.00805 & 0.00000 \\
\hline 51 & 1.14482 & 0.00790 & 0.00018 & 1.16922 & 0.00805 & 0.00000 \\
\hline 52 & 1.15420 & 0.00819 & 0.00030 & 1.17884 & 0.00823 & 0.00017 \\
\hline 53 & 1.16401 & 0.00850 & 0.00030 & 1.18887 & 0.00850 & 0.00028 \\
\hline 54 & 1.17412 & 0.00869 & 0.00019 & 1.19930 & 0.00878 & 0.00028 \\
\hline 55 & 1.18469 & 0.00900 & 0.00032 & 1.21017 & 0.00906 & 0.00028 \\
\hline 56 & 1.19589 & 0.00945 & 0.00044 & 1.22146 & 0.00933 & 0.00028 \\
\hline 57 & 1.20744 & 0.00966 & 0.00021 & 1.23320 & 0.00961 & 0.00028 \\
\hline 58 & 1.21936 & 0.00988 & 0.00022 & 1.24539 & 0.00989 & 0.00028 \\
\hline 59 & 1.23153 & 0.00998 & 0.00010 & 1.25804 & 0.01016 & 0.00028 \\
\hline 60 & 1.24409 & 0.01020 & 0.00023 & 1.27117 & 0.01044 & 0.00028 \\
\hline 61 & 1.25691 & 0.01031 & 0.00011 & 1.28479 & 0.01071 & 0.00028 \\
\hline 62 & 1.27000 & 0.01041 & 0.00011 & 1.29891 & 0.01099 & 0.00028 \\
\hline 63 & 1.28370 & 0.01078 & 0.00037 & 1.31354 & 0.01127 & 0.00028 \\
\hline 64 & 1.29769 & 0.01090 & 0.00012 & 1.32871 & 0.01154 & 0.00028 \\
\hline 65 & 1.31199 & 0.01102 & 0.00012 & 1.34441 & 0.01182 & 0.00028 \\
\hline 66 & 1.32679 & 0.01128 & 0.00026 & 1.36067 & 0.01209 & 0.00028 \\
\hline 67 & 1.34210 & 0.01154 & 0.00026 & 1.37750 & 0.01237 & 0.00028 \\
\hline 68 & 1.35777 & 0.01168 & 0.00013 & 1.39492 & 0.01265 & 0.00028 \\
\hline 69 & 1.37382 & 0.01181 & 0.00014 & 1.41295 & 0.01292 & 0.00028 \\
\hline 70 & 1.39043 & 0.01210 & 0.00028 & 1.43160 & 0.01320 & 0.00028 \\
\hline 71 & 1.40726 & 0.01210 & 0.00001 & 1.45090 & 0.01348 & 0.00028 \\
\hline 72 & 1.42470 & 0.01239 & 0.00029 & 1.47085 & 0.01375 & 0.00028 \\
\hline 73 & 1.44259 & 0.01255 & 0.00016 & 1.49148 & 0.01403 & 0.00028 \\
\hline 74 & 1.46113 & 0.01286 & 0.00031 & 1.51282 & 0.01430 & 0.00028 \\
\hline 75 & 1.47995 & 0.01288 & 0.00002 & 1.53488 & 0.01458 & 0.00028 \\
\hline 76 & 1.49925 & 0.01304 & 0.00017 & 1.55768 & 0.01486 & 0.00028 \\
\hline 7 & 1.51930 & 0.01337 & 0.00033 & 1.58125 & 0.01513 & 0.00028 \\
\hline 78 & 1.53965 & 0.01339 & 0.00003 & 1.60562 & 0.01541 & 0.00028 \\
\hline 79 & 1.56104 & 0.01389 & 0.00050 & 1.63081 & 0.01569 & 0.00028 \\
\hline 80 & 1.58278 & 0.01393 & 0.00004 & 1.65684 & 0.01596 & 0.00028 \\
\hline 81 & 1.60514 & 0.01413 & 0.00020 & 1.68374 & 0.01624 & 0.00028 \\
\hline 82 & 1.62840 & 0.01449 & 0.00037 & 1.71155 & 0.01651 & 0.00028 \\
\hline 83 & 1.65235 & 0.01471 & 0.00021 & 1.74029 & 0.01679 & 0.00028 \\
\hline 84 & 1.67701 & 0.01493 & 0.00022 & 1.76999 & 0.01707 & 0.00028 \\
\hline 85 & 1.70242 & 0.01515 & 0.00023 & 1.80069 & 0.01734 & 0.00028 \\
\hline 86 & 1.72861 & 0.01538 & 0.000023 & 1.83241 & 0.01762 & 0.00028 \\
\hline 87 & 1.75593 & 0.01580 & 0.00042 & 1.86521 & 0.01790 & 0.00028 \\
\hline 88 & 1.78380 & 0.01588 & 0.000007 & 1.89910 & 0.01817 & 0.00028 \\
\hline 89 & 1.81291 & 0.01632 & 0.00044 & 1.93414 & 0.01845 & 0.00028 \\
\hline 90 & 1.84264 & 0.01640 & 0.00008 & 1.97035 & 0.01872 & 0.00028 \\
\hline
\end{tabular}

Notes: MAGT - Masters Are-Graded Tables. $R_{k}$ is the inverse of the aze-factors in MAGT. The MAGT ace-fectors ore for the $5 \mathrm{~K}$ through half murathon events. The ape-factors from the present atudy are from the estimates in line 22 in tuble $1 . D_{k}$ is the percentage change in $R_{k}: D_{k}=\left(R_{k} / R_{k-1}\right)-1$. 
The second conclusion is that the values of $R_{k}$ are always higher for the present study. By age 90 the value of $R_{k}$ is about $7 \%$ higher than the MAGT value. MAGT thus assumes that men slow down at a slower rate than seems warranted by the data.

Table 3 presents five sets of values of $R_{k}$ implied by the present study. The values are based on the coefficient estimates in lines 20-24 in table 1 , which were obtained using the frontier estimation procedure. The starting values of $R_{k}$ (at age 35) are taken from MAGT. The values of $R_{k}$ are presented through age 100 , although the values for about age 83 and above are extrapolations beyond the end of the estimation range and should be interpreted with more caution.

As noted in section III, the 200 meter results are somewhat suspect. If the 200 meter results are ignored, table 3 shows that beginning with age 79 the values of $R_{k}$ increase with the length of the race. At age 90 the values are 1.6979 for 100 meters, 1.9704 for 400 meters through the half marathon, 2.2169 for $30 \mathrm{~K}$ and 20 miles, and 2.8573 for the marathon. If the best marathon time is taken to be 2 hours and 6 minutes, the value of $R_{k}$ for the marathon implies that the best time for a 90 year old is 6 hours $(2.8573$ times 2 hours and 6 minutes). At age 100 the four values of $R_{k}$ are, respectively, $2.0265,2.4076$, 3.1398 , and 5.1821 , although again these values are extrapolations way beyond the end of the estimation period.

Coming back to the MAGT values, although not shown in table 2, the MAGT value of $R_{k}$ at age 90 for 100 meters is 1.6736. This is again lower than the value of 1.6979 in table 3 , although in this case the values are quite close. The MAGT value of $R_{k}$ at age 90 for the marathon is 1.8171 , which is considerably lower than the value of 2.8573 in table 3 . The MAGT values imply that the slowdown rates for the marathon are smaller than they are for the $5 \mathrm{~K}$ through half marathon events, which is the opposite of what the empirical results seem to show and of what is presented in table 3. Using a best marathon time of 2 hours and 6 minutes, the MAGT value of 1.8171 for age 90 implies that the best time for a 90 year old is 3 hours and 49 minutes, which compares to the above estimate of 6 hours using the results in this study.

\section{Use of Table 3 by Individuals}

The key assumption of this paper so far is that $b_{k}$ when plotted against $k$ looks like that depicted in figure 2 from age $k_{2}$ on. An additional assumption is needed to justify the use of table 3 by a single individual. This assumption is that the difference in figure 1 between an individual's position on the horizontal axis and $b_{k}$ does not change as $b_{k}$ changes with age. If this assumption is true, it simply means that the individual's times are increasing at the same percentage rate as the record times are increasing. Obviously, injury or illness will increase one's distance from $b_{k}$. Also, if average runners slow down at a different rate from elite runners, then the distance from $b_{k}$ for an average runner will be changing over time, thus making the results in table 3 unreliable. Finally, if prolonged running wears out parts of the body-the opposite of use-it-or-lose-it-then one's distance from $b_{k}$ will change over time as a function of how much past running has been done. This will also make the results in table 3 unreliable.

Given the assumption that one's distance from $b_{k}$ in figure 1 is constant over time and given an estimate of one's best time ever in the event, the values of $R_{k}$ in table 3 can be used to compute one's projected times by age. Race officials can also use the values to adjust each runner's time for his age.

\section{Comparison to the $\mathrm{VO}_{2 \max }$ Results}

A common measure of aerobic capacity in physiology is $\mathrm{VO}_{2 \max }$. It is well known that $\mathrm{VO}_{2 \max }$ declines with age, and it is of interest to see how this decline compares to the decline in running performance estimated in this study. There seems to be nothing in the physiological literature for $\mathrm{VO}_{2 \max }$ that is equivalent to table 3 , but there are some relevant results. Rogers et al. (1990) report a decline of $4.1 \%$ in 7.5 years in master athletes whose average age at the start was 62 . This is a yearly fall of 0.0054 , which compares to 0.0115 in table 3 for age 64 and the events 400 meters-half marathon. Heath et al. (1981) report between a $5 \%$ and $9 \%$ decline per decade for subjects between the ages of 50 and 62 . A 5\% decline is a yearly fall of 0.0049 , and a $9 \%$ decline is a yearly fall of 0.0087 . These numbers compare to 0.0096 
Tagle 3. - Estimated age Factors

$\boldsymbol{R}_{\ell}=$ Projected tIME FOR Age $k$ DIVIDEd by OVERALl. best TIME

$D_{k}=$ Percentage change in $R_{k}$

\begin{tabular}{|c|c|c|c|c|c|c|c|c|c|c|}
\hline \multirow[b]{2}{*}{ Age } & \multicolumn{2}{|c|}{100 Meters } & \multicolumn{2}{|c|}{200 Meters } & \multicolumn{2}{|c|}{$\begin{array}{c}400 \text { Meters- } \\
\text { Half Marathon }\end{array}$} & \multicolumn{2}{|c|}{$30 \mathrm{~K}, 20$ Miles } & \multicolumn{2}{|c|}{ Marathon } \\
\hline & $R_{\mathrm{h}}$ & $D_{k}$ & $\boldsymbol{R}_{k}$ & $D_{\alpha}$ & $R_{k}$ & $D_{k}$ & $R_{k}$ & $D_{k}$ & $R_{k}$ & $D_{k}$ \\
\hline 35 & 1.0368 & 0.0046 & 1.0442 & 0.0068 & 1.0284 & 0.0080 & 1.0284 & 0.0045 & 1.0143 & 0.0053 \\
\hline 36 & 1.0416 & 0,0046 & 1.0512 & 0.0068 & 1.0367 & 0.0080 & 1.0330 & 0.0045 & 1.0197 & 0.0053 \\
\hline 37 & 1.0463 & 0.0046 & 1.0583 & 0.0068 & 1.0450 & 0.0080 & 1.0376 & 0.0045 & 1.0251 & 0.0053 \\
\hline 38 & 1.0512 & 0.0046 & 1.0655 & 0.0068 & 1.0534 & 0.0080 & 1.0422 & 0.0045 & 1.0305 & 0.0053 \\
\hline 39 & 1.0560 & 0.0046 & 1.0727 & 0.0068 & 1.0619 & 0.0080 & 1.0469 & 0.0045 & 1.0360 & 0.0053 \\
\hline 40 & 1.0608 & 0.0046 & 1.0800 & 0.0068 & 1.0705 & 0.0080 & 1.0515 & 0.0045 & 1.0415 & 0.0053 \\
\hline 41 & 1.0657 & $0.0 \times 46$ & 1.0873 & 0.0068 & 1.0791 & 0.0080 & 1.0562 & 0.0045 & 1.0470 & 0.0053 \\
\hline 42 & 1.0706 & 0.0046 & 1.0946 & 0.0068 & 1.0878 & 0.0080 & 1.0610 & 0.0045 & 1.0526 & 0.0053 \\
\hline 43 & 1.0755 & 0.0046 & 1.1020 & 0.0068 & 1.0965 & 0.0080 & 1.0657 & 0.0045 & 1.0581 & 0.0053 \\
\hline 44 & 1.0804 & 0.0046 & 1.11095 & 0.0068 & 1.1054 & 0.0080 & 1.0704 & 0.0045 & 1.0637 & 0.0053 \\
\hline 45 & 1.0854 & 0.0046 & 1.1170 & 0.0068 & 1.1143 & 0.0080 & 1.0752 & 0.0045 & 1.0694 & 0.0053 \\
\hline 46 & 1.0904 & 0.0046 & 1.1245 & 0.0068 & 1.1233 & 0.0080 & 1.0800 & 0.0045 & 1.0751 & 0.0053 \\
\hline 47 & 1.0954 & 0.0046 & 1.1321 & 0.0068 & 1.1323 & 0.0080 & 1.0849 & 0.0045 & 1.0808 & 0.0053 \\
\hline 48 & 1.1004 & 0.0046 & 1.1398 & 0.0068 & 1.1414 & 0.0080 & 1.0897 & 0.0045 & 1.0865 & 0.0053 \\
\hline 49 & 1.1055 & 0.0046 & 1.1475 & 0.0068 & 1.1506 & 0.0080 & 1.0946 & 0.0045 & 1.0922 & 0.0053 \\
\hline 50 & 1.1107 & 0.0048 & 1.1553 & 0.0068 & 1.1599 & 0.0080 & 1.0994 & 0.0045 & 1.0980 & 0.0053 \\
\hline 51 & 1.1164 & 0.0051 & 1.1631 & 0.0068 & 1.1692 & 0.0080 & 1.1043 & 0.0045 & 1.1039 & 0.0053 \\
\hline 52 & 1.1224 & 0.0054 & 1.1709 & 0.0068 & 1.1788 & 0.0082 & 1.1094 & 0.0046 & 1.1097 & 0.0053 \\
\hline 53 & 1.1287 & 0.0056 & 1.1789 & 0.0068 & 1.1889 & 0.0085 & 1.1153 & 0.0053 & 1.1156 & 0.0053 \\
\hline 54 & 1.1354 & 0.0059 & 1.1868 & 0.0068 & 1.1993 & 0.0088 & 1.1220 & 0.0060 & 1.1215 & 0.0053 \\
\hline 55 & 1.1424 & 0.0062 & 1.1949 & 0.0068 & 1.2102 & 0.0091 & 1.1296 & 0.0067 & 1.1275 & 0.0053 \\
\hline 56 & 1.1499 & 0.0065 & 1.2029 & 0.0068 & 1.2215 & 0.0093 & 1.1380 & 0.0074 & 1.1334 & 0.0053 \\
\hline 57 & 1.1577 & 0.0068 & 1.2111 & 0.0068 & 1.2332 & 0.0096 & 1.1472 & 0.0081 & 1.1395 & 0.0053 \\
\hline 58 & 1.1659 & 0.0071 & 1.2193 & 0.0068 & 1.2454 & 0.0099 & 1.1574 & 0.0089 & 1.1455 & 0.0053 \\
\hline 59 & 1.1745 & 0.0074 & 1.2275 & 0.0068 & 1.2580 & 0.0102 & 1.1684 & 0.0096 & 1.1516 & 0.0053 \\
\hline 60 & 1.1835 & 0.0077 & 1.2358 & 0.0068 & 1.2712 & 0.0104 & 1.1804 & 0.0103 & 1.1594 & 0.0068 \\
\hline 61 & 1.1929 & 0.0079 & 1.2442 & 0.0068 & 1.2848 & 0.0107 & 1.1934 & 0.0110 & 1.1690 & 0.0083 \\
\hline 62 & 1.2027 & 0.0082 & 1.2526 & 0.0068 & 1.2989 & 0.0110 & 1.2073 & 0.0117 & 1.1806 & 0.0099 \\
\hline 63 & 1.2129 & 0.0085 & 1.2611 & 0.0068 & 1.3135 & 0.0113 & 1.2223 & 0.0124 & 1.1940 & 0.0114 \\
\hline 64 & 1.2236 & 0.0088 & 1.2709 & 0.0078 & 1.3287 & 0.0115 & 1.2383 & 0.0131 & 1.2094 & 0.0129 \\
\hline 65 & 1.2347 & 0.0091 & 1.2821 & 0.0088 & 1.3444 & 0.0118 & 1.2554 & 0.0138 & 1.2270 & 0.0145 \\
\hline 66 & 1.2463 & 0.0094 & 1.2946 & 0.0098 & 1.3607 & 0.0121 & 1.2736 & 0.0145 & 1.2466 & 0.0160 \\
\hline $6 ?$ & 1.2584 & 0.0097 & 1.3085 & 0.0108 & 1.3775 & 0.0124 & 1.2930 & 0.0152 & I.2685 & 0.0175 \\
\hline 68 & 1.2709 & 0.0100 & 1.3239 & 0.0118 & 1.3949 & 0.0126 & 1.3136 & 0.0159 & 1.2927 & 0.0191 \\
\hline 69 & 1.2839 & 0.0102 & 1.3408 & 0.0128 & 1.4129 & 0.0129 & 1.3355 & 0.0166 & 1.3193 & 0.0206 \\
\hline 70 & 1.2974 & 0.0105 & 1.3593 & 0.0138 & 1.4316 & 0.0132 & 1.3586 & 0.0174 & 1.3486 & 0.0222 \\
\hline 71 & 1.3115 & 0.0108 & 1.3793 & 0.0147 & 1.4509 & 0.0135 & 1.3832 & 0.0181 & 1.3805 & 0.0237 \\
\hline 72 & 1.3260 & 0.0111 & 1.4010 & 0.0157 & 1.4708 & 0.0138 & 1.4091 & 0.0188 & 1.4153 & 0.0252 \\
\hline 73 & 1.3411 & 0.0114 & 1.4244 & 0.0167 & 1.4915 & 0.0140 & 1.4366 & 0.0195 & 1.4532 & 0.0268 \\
\hline 74 & 1.3568 & 0.0117 & 1.4497 & 0.0177 & 1.5128 & 0.0143 & 1.4656 & 0.0202 & 1.4944 & 0.0283 \\
\hline 75 & 1.3730 & 0.0120 & 1.4768 & 0.0187 & 1.5349 & 0.0146 & 1.4962 & 0.0209 & 1.5390 & 0.0298 \\
\hline 76 & 1.3898 & 0.0123 & 15060 & 0.0197 & 1.5577 & 0.0149 & 1.5285 & 0.0216 & 1.5872 & 0.0314 \\
\hline 77 & 1.4072 & 0.0125 & 1.5372 & 0.0207 & 1.5813 & 0.0151 & 1.5626 & 0.0223 & 1.6395 & 0.0329 \\
\hline 78 & 1.4253 & 0.0128 & 15705 & 0.0217 & 1.6056 & 0.0154 & 1.5986 & 0.0230 & 1.6960 & 0.0345 \\
\hline 79 & 1.4440 & 0.0131 & 1.6062 & 0.0227 & 1.6308 & 0.0157 & 1.6365 & 0.0237 & 1.7570 & 0.0360 \\
\hline 80 & 1.4633 & 0.0134 & 1.6442 & 0.0237 & 1.6568 & 0.0160 & 1.6765 & 0.0244 & 1.8229 & 0.0375 \\
\hline 81 & 1.4834 & 0.0137 & 1.6848 & 0.0247 & 1.6837 & 0.0162 & 1.7187 & 0.0251 & 1.8941 & 0.0391 \\
\hline 82 & 1.5041 & 0.0140 & 1.7281 & 0.0257 & 1.7115 & 0.0165 & 1.7631 & 0.0259 & 1.9710 & 0.0406 \\
\hline 83 & 1.5255 & 0.0143 & 1.7742 & 0.0267 & 1,7403 & 0.0168 & 1.8099 & 0.0266 & 2.0541 & 0.0421 \\
\hline 84 & 1.5477 & 0.0146 & 1.8233 & 0.0277 & 1.7700 & 0.0171 & 1.8593 & 0.0273 & 2.1438 & 0.0437 \\
\hline 85 & 1.5707 & 0.0148 & 1.8756 & 0.0287 & 1.8007 & 0.0173 & 1.9113 & 0.0280 & 2.2407 & 0.0452 \\
\hline 86 & 1.5944 & 0.0151 & 1.9312 & 0.0297 & 1.8324 & 0.0176 & 1.9662 & 0.0287 & 2.3455 & 0.0467 \\
\hline 87 & 1.6190 & 0.0154 & 1.9904 & 0.0307 & 1.8652 & 0.0179 & 2.0240 & 0.0294 & 2.4587 & 0.0483 \\
\hline 88 & 1.6444 & 0.0157 & 2.0534 & 0.0316 & 1.8991 & 0.0182 & 2.0849 & 0.0301 & 2.5812 & 0.0498 \\
\hline 89 & 1.6707 & 0.0160 & 2.1204 & 0.0326 & 1.9341 & 0.0185 & 2.1491 & 0.0308 & 2.7138 & 0.0514 \\
\hline 90 & 1.6979 & 0.0163 & 2.1917 & 0.0336 & 1.9704 & 0.0187 & 2.2169 & 0.0315 & 2.8573 & 0.0529 \\
\hline 91 & 1.7260 & 0.0166 & 2.2677 & 0.0346 & 2.0078 & 0.0190 & 2.2883 & 0.0322 & 3.0129 & 0.0544 \\
\hline 92 & 1.7551 & 0.0169 & 2.3484 & 0.0356 & 2.0465 & 0.0193 & 2.3637 & 0.0329 & 3.1815 & 0.0560 \\
\hline 93 & 1.7852 & 0.0171 & 2.4345 & 0.0366 & 20865 & 0.0196 & 2.4432 & 0.0336 & 3.3645 & 0.0575 \\
\hline 94 & 1.8162 & 0.0174 & 2.5260 & 0.0376 & 2.1279 & 0.0198 & 2.5272 & 0.0344 & 3.5631 & 0.0590 \\
\hline 95 & 1.8484 & 0.0177 & 2.6235 & 0.0386 & 2.1707 & 0.0201 & 2.6158 & 0.0351 & 3.7790 & 0.0606 \\
\hline 96 & 1.8817 & 0.0180 & 2.7275 & 0.0396 & 2.2149 & 0.0204 & 2.7094 & 0.0358 & 4.0137 & 0.0621 \\
\hline 97 & 1.9161 & 0.0183 & 2.8382 & 0.0406 & 2.2607 & 0.0207 & 2.8082 & 0.0365 & 4.2692 & 0.0636 \\
\hline 98 & 1.9516 & 0.0186 & 2.9562 & 0.0416 & 2.3080 & 0.0209 & 2.9127 & 0.0372 & 4.5475 & 0.0652 \\
\hline 99 & 1.9884 & 0.0189 & 3.0821 & 0.0426 & 2.3569 & 0.0212 & 3.0231 & 0.0379 & 4.8510 & 0.0667 \\
\hline 100 & 2.0265 & 0.0191 & 3.2165 & 0.0436 & 2.4076 & 0.0215 & 3.1398 & 0.0386 & 5.1821 & 0.0683 \\
\hline
\end{tabular}

Notes: The values for $R_{35}$ tre taken from MAGT. The values for $R_{k}$ are computed using the coeficient estimates in lines $20-24$ in table 1 . $D_{k}=R_{k} / R_{k-1}-\mathrm{I}$. 
in table 3 for age 57. Both of these studies thus show a smaller $\mathrm{VO}_{2 \max }$ decline than the estimated decline in performance for the events 400 meters-half marathon in table 3 . Note in table 3 , however, that the derivative for the marathon is 0.0053 until age 60 and the derivative for $30 \mathrm{~K}, 20$ miles is 0.0045 until age 52 . These numbers are close to the $\mathrm{VO}_{2 \max }$ results.

Dehn and Bruce (1972) provide an interesting regression to compare with the present results. Using a sample of ages between 40 and 69 , they regress $\mathrm{VO}_{2 \max }$ adjusted for body weight on age. The coefficient estimate on age is -0.362 , and the estimate of the constant term is 52.741 . One can compute from this regression the percentage fall in $\mathrm{VO}_{2 \max }$ at different ages, using the predicted value from this regression for the given age as the base value from which to compute the percentage. The results for selected ages compared to the results for 400 meters-half marathon in table 3 are:

$\begin{array}{lccccccc}\text { Age: } & 40 & 50 & 60 & 70 & 80 & 90 & 100 \\ \text { VO }_{2 \max }: & .0095 & .0105 & .0117 & .0132 & .0152 & .0180 & .0210 \\ \text { Table 3: } & .0080 & .0080 & .0104 & .0132 & .0160 & .0187 & .0215\end{array}$

The agreement in this case from age 60 on is remarkable, although for ages 40 and 50 the estimated decline in table 3 is noticeably less than it is from the $\mathrm{VO}_{2 \max }$ regression. Also, estimates from the $\mathrm{VO}_{2 \max }$ regression for ages 50 and 60 are greater than the estimates from the two other studies reported above, and so the present comparisons are quite tentative. An interesting question for future work is whether the $\mathrm{VO}_{2 \max }$ results for the older ages (say 75 and above) can be used to help one estimate the slowdown rate at the older ages, where the small $N_{k}$ problem is so severe.

\section{The Field Events}

The small $N_{k}$ problem is probably more serious for the field events than it is for the track and road racing events. This is particularly true for the shot put, discus throw, hammer throw, and javelin throw, where in many meets the weights of the relevant objects are less for older competitors. For this study only the results for the heaviest weights were used because these were the only results for which observations began at age 35.

The same procedure was followed for the field events as was followed for the other events. The $\log$ of the distance was used as the variable to be explained, and $\alpha_{2}$ and $\alpha_{5}$ are now expected to be negative since distance falls with age. ${ }^{8}$ Also, $\epsilon_{k}$ is

\footnotetext{
"When the phrase "slow down" is applied to the field events, it obviously refers to smaller distances rather than larger times.
}

Table 4.-The Estimation Results for the Field Events

\begin{tabular}{|c|c|c|c|c|c|c|c|c|c|c|c|c|c|c|}
\hline \multirow[b]{2}{*}{ Line } & \multirow[b]{2}{*}{ Event } & \multirow[b]{2}{*}{$\hat{\alpha}_{2}$} & \multirow[b]{2}{*}{$\operatorname{SE}\left(\hat{\alpha}_{2}\right)$} & \multirow[b]{2}{*}{$\hat{k}_{3}$} & \multirow[b]{2}{*}{$\operatorname{SE}\left(\hat{k}_{3}\right)$} & \multirow[b]{2}{*}{$\hat{\alpha}_{s}$} & \multirow[b]{2}{*}{$\operatorname{SE}\left(\hat{\alpha}_{5}\right)$} & \multicolumn{4}{|c|}{ Derivative at Age } & \multirow[b]{2}{*}{ SE } & \multirow{2}{*}{$\begin{array}{l}\text { No. } \\
\text { Obs. }\end{array}$} & \multirow{2}{*}{$\begin{array}{l}\text { Max } \\
\text { Age }\end{array}$} \\
\hline & & & & & & & & 50 & 60 & 75 & 95 & & & \\
\hline $\begin{array}{l}1 \\
2 \\
3 \\
4 \\
5 \\
6 \\
7 \\
8\end{array}$ & $\begin{array}{l}\text { HJ } \\
\text { PV } \\
\text { LJ } \\
\text { TJ } \\
\text { SP } \\
\text { DT } \\
\text { HT } \\
\text { JT }\end{array}$ & $\begin{array}{l}-.0093 \\
-.0130 \\
-.0140 \\
-.0125 \\
-.0281 \\
-.0280 \\
-.0275 \\
-.0273\end{array}$ & $\begin{array}{l}.0009 \\
.0010 \\
.0007 \\
.0012 \\
.0010 \\
.0013 \\
.0009 \\
.0010\end{array}$ & $\begin{array}{l}51.5 \\
64.1 \\
74.0 \\
53.1 \\
- \\
- \\
-\end{array}$ & $\begin{array}{l}6.2 \\
2.1 \\
1.9 \\
9.6 \\
- \\
- \\
-\end{array}$ & $\begin{array}{c}-.00015 \\
-.00108 \\
-.00158 \\
-.00015 \\
= \\
= \\
=\end{array}$ & $\begin{array}{c}.00003 \\
.00019 \\
.00030 \\
.00006 \\
= \\
= \\
=\end{array}$ & $\begin{array}{l}-.0093 \\
-.0130 \\
-.0140 \\
-.0125 \\
-.0281 \\
-.0280 \\
-.0275 \\
-.0273\end{array}$ & $\begin{array}{l}-.0119 \\
-.0130 \\
-.0140 \\
-.0145 \\
-.0281 \\
-.0280 \\
-.0275 \\
-.0273\end{array}$ & $\begin{array}{l}-.0163 \\
-.0366 \\
-.0173 \\
-.0189 \\
-.0281 \\
-.0280 \\
-.0275 \\
-.0273\end{array}$ & $\begin{array}{c}-.0223 \\
-.0798 \\
-.0805 \\
-.0247 \\
= \\
= \\
=\end{array}$ & $\begin{array}{l}.017 \\
.036 \\
.040 \\
.022 \\
.061 \\
.070 \\
.049 \\
.059\end{array}$ & $\begin{array}{l}26 \\
31 \\
26 \\
27 \\
23 \\
20 \\
21 \\
26\end{array}$ & $\begin{array}{l}90 \\
86 \\
95 \\
83 \\
80 \\
78 \\
76 \\
77\end{array}$ \\
\hline $9^{a}$ & \multicolumn{14}{|c|}{ Pooled } \\
\hline \multicolumn{15}{|c|}{ Frontier Method } \\
\hline $\begin{array}{l}10 \\
11 \\
12 \\
13 \\
14\end{array}$ & $\begin{array}{l}1 \\
2 \\
3 \\
4 \\
9\end{array}$ & $\begin{array}{l}-.0095 \\
-.0129 \\
-.0135 \\
-.0129 \\
-.0266\end{array}$ & $\begin{array}{l}- \\
\bar{z} \\
-\end{array}$ & $\begin{array}{l}62.7 \\
65.8 \\
75.4 \\
60.5 \\
-\end{array}$ & $\begin{array}{l}\bar{z} \\
\bar{z}\end{array}$ & $\begin{array}{c}-.00030 \\
-.00125 \\
-.00194 \\
-.00018 \\
-\end{array}$ & $\begin{array}{l}\bar{z} \\
\bar{z}\end{array}$ & $\begin{array}{l}-.0095 \\
-.0129 \\
-.0135 \\
-.0129 \\
-.0266\end{array}$ & $\begin{array}{l}-.0095 \\
-.0129 \\
-.0135 \\
-.0129 \\
-.0266\end{array}$ & $\begin{array}{l}-.0170 \\
-.0358 \\
-.0135 \\
-.0180 \\
-.0266\end{array}$ & $\begin{array}{l}-.0290 \\
-.0856 \\
-.0895 \\
-.0251 \\
-\end{array}$ & $\begin{array}{l}\bar{z} \\
\bar{z}\end{array}$ & $\begin{array}{l}26 \\
31 \\
26 \\
27 \\
90\end{array}$ & $\begin{array}{l}90 \\
86 \\
95 \\
83 \\
80\end{array}$ \\
\hline
\end{tabular}

Notes: Max Age = oldest age used in the sample period. HJ = hiph jump; PV = pote vault; $L J$ - long jump; TJ - triple jump; SP - shot put, 16 pounds; DT - discus throw, $2 \mathrm{kgs}$; HT = hammer throw, 16 pounds; JT = javelin throw, 800 grams.

The pooled equations are 5-8.

The frontier method used for this line above. 
Table 5.-Estimated Age Factors for the Field Events

$R_{k}=$ PROJECTED TIME FOR ACE $k$ DIVIDED BY OVERALL BEST TIME

$D_{k}=$ PERCENTAGE CHANGE IN $R_{k}$

\begin{tabular}{|c|c|c|c|c|c|c|c|c|c|c|}
\hline \multirow[b]{2}{*}{ Age } & \multicolumn{2}{|c|}{ High Jump } & \multicolumn{2}{|c|}{ Pole Vault } & \multicolumn{2}{|c|}{ Long Jump } & \multicolumn{2}{|c|}{ Triple Jump } & \multicolumn{2}{|c|}{$\begin{array}{l}\text { Throwing } \\
\text { Events }\end{array}$} \\
\hline & $R_{k}$ & $D_{k}$ & $R_{k}$ & $D_{k}$ & $R_{k}$ & $D_{k}$ & $R_{k}$ & $D_{k}$ & $R_{k}$ & $D_{k}$ \\
\hline 35 & 0.9381 & -0.0095 & 0.9302 & -0.0129 & 0.9328 & -0.0135 & 0.9311 & -0.0129 & 0.9381 & -0.0266 \\
\hline 36 & 0.9291 & -0.0095 & 0.9182 & -0.0129 & 0.9202 & -0.0135 & 0.9191 & -0.0129 & 0.9132 & -0.0266 \\
\hline 37 & 0.9203 & -0.0095 & 0.9063 & -0.0129 & 0.9078 & -0.0135 & 0.9072 & -0.0129 & 0.8889 & -0.0266 \\
\hline 38 & 0.9115 & -0.0095 & 0.8946 & -0.0129 & 0.8955 & -0.0135 & 0.8955 & -0.0129 & 0.8652 & -0.0266 \\
\hline 39 & 0.9028 & -0.0095 & 0.8830 & -0.0129 & 0.8834 & -0.0135 & 0.8840 & -0.0129 & 0.8423 & -0.0266 \\
\hline 40 & 0.8942 & -0.0095 & 0.8716 & -0.0129 & 0.8715 & -0.0135 & 0.8725 & -0.0129 & 0.8199 & -0.0266 \\
\hline 41 & 0.8857 & -0.0095 & 0.8603 & -0.0129 & 0.8597 & -0.0135 & 0.8613 & -0.0129 & 0.7981 & -0.0266 \\
\hline 42 & 0.8772 & -0.0095 & 0.8492 & -0.0129 & 0.8481 & -0.0135 & 0.8502 & -0.0129 & 0.7769 & -0.0266 \\
\hline 43 & 0.8689 & -0.0095 & 0.8382 & -0.0129 & 0.8366 & -0.0135 & 0.8392 & -0.0129 & 0.7562 & -0.0266 \\
\hline 44 & 0.8606 & -0.0095 & 0.8274 & -0.0129 & 0.8253 & -0.0135 & 0.8284 & -0.0129 & 0.7361 & -0.0266 \\
\hline 45 & 0.8524 & -0.0095 & 0.8167 & -0.0129 & 0.8142 & -0.0135 & 0.8177 & -0.0129 & 0.7166 & -0.0266 \\
\hline 46 & 0.8442 & -0.0095 & 0.8061 & -0.0129 & 0.8032 & -0.0135 & $0.807 i$ & -0.0129 & 0.6975 & -0.0266 \\
\hline 47 & 0.8362 & -0.0095 & 0.7957 & -0.0129 & 0.7923 & -0.0135 & 0.7967 & -0.0129 & 0.6790 & -0.0266 \\
\hline 48 & 0.8282 & -0.0095 & 0.7854 & -0.0129 & 0.7816 & -0.0135 & 0.7864 & -0.0129 & 0.6609 & -0.0266 \\
\hline 49 & 0.8203 & -0.0095 & 0.7753 & -0.0129 & 0.7710 & -0.0135 & 0.7762 & -0.0129 & 0.6433 & -0.0266 \\
\hline 50 & 0.8125 & -0.0095 & 0.7652 & -0.0129 & 0.7606 & -0.0135 & 0.7662 & -0.0129 & 0.6262 & -0.0266 \\
\hline 51 & 0.8047 & -0.0095 & 0.7553 & -0.0129 & 0.7503 & -0.0135 & 0.7563 & -0.0129 & 0.6096 & -0.0266 \\
\hline 52 & 0.7971 & -0.0095 & 0.7456 & -0.0129 & 0.7402 & -0.0135 & 0.7466 & -0.0129 & 0.5934 & -0.0266 \\
\hline 53 & 0.7894 & -0.0095 & 0.7359 & -0.0129 & 0.7302 & -0.0135 & 0.7369 & -0.0129 & 0.5776 & -0.0266 \\
\hline 54 & 0.7819 & -0.0095 & 0.7264 & -0.0129 & 0.7203 & -0.0135 & 0.7274 & -0.0129 & 0.5623 & -0.0266 \\
\hline 55 & 0.7745 & -0.0095 & 0.7170 & -0.0129 & 0.7106 & -0.0135 & 0.7180 & -0.0129 & 0.5473 & -0.0266 \\
\hline 56 & 0.7671 & -0.0095 & 0.7077 & -0.0129 & 0.7010 & -0.0135 & 0.7088 & -0.0129 & 0.5328 & -0.0266 \\
\hline 57 & 0.7598 & -0.0095 & 0.6986 & -0.0129 & 0.6915 & -0.0135 & 0.6996 & -0.0129 & 0.5186 & -0.0266 \\
\hline 58 & 0.7525 & -0.0095 & $0.68 \%$ & -0.0129 & 0.6822 & -0.0135 & 0.6906 & -0.0129 & 0.5048 & -0.0266 \\
\hline 59 & 0.7453 & -0.0095 & 0.6806 & -0.0129 & 0.6729 & -0.0135 & 0.6817 & -0.0129 & 0.4914 & -0.0266 \\
\hline 60 & 0.7382 & -0.0095 & 0.6718 & -0.0129 & 0.6639 & -0.0135 & 0.6729 & -0.0129 & 0.4783 & -0.0266 \\
\hline 61 & 0.7312 & -0.0095 & 0.6632 & -0.0129 & 0.6549 & -0.0135 & 0.6641 & -0.0131 & 0.4656 & -0.0266 \\
\hline 62 & 0.7242 & -0.0095 & 0.6546 & -0.0129 & 0.6460 & -0.0135 & 0.6552 & -0.0134 & 0.4533 & -0.0266 \\
\hline 63 & 0.7172 & -0.0097 & 0.6461 & -0.0129 & 0.6373 & -0.0135 & 0.6461 & -0.0138 & 0.4412 & -0.0266 \\
\hline 64 & 0.7098 & -0.0103 & 0.6378 & -0.0129 & 0.6287 & -0.0135 & 0.6370 & -0.0141 & 0.4295 & -0.0266 \\
\hline 65 & 0.7020 & -0.0109 & 0.6295 & -0.0129 & 0.6202 & -0.0135 & 0.6277 & -0.0145 & 0.4181 & -0.0266 \\
\hline 66 & 0.6940 & -0.0115 & 0.6210 & -0.0134 & 0.6118 & -0.0135 & 0.6184 & -0.0149 & 0.4070 & -0.0266 \\
\hline 67 & 0.6855 & -0.0121 & 0.6112 & -0.0159 & 0.6035 & -0.0135 & 0.6090 & -0.0152 & 0.3961 & -0.0266 \\
\hline 68 & 0.6768 & -0.0127 & 0.5999 & -0.0184 & 0.5954 & -0.0135 & 0.5995 & -0.0156 & 0.3856 & -0.0266 \\
\hline 69 & 0.6678 & -0.0133 & 0.5874 & -0.0209 & 0.5873 & -0.0135 & 0.5900 & -0.0159 & 0.3754 & -0.0266 \\
\hline 70 & 0.6585 & -0.0139 & 0.5736 & -0.0234 & 0.5794 & -0.0135 & 0.5804 & -0.0163 & 0.3654 & -0.0266 \\
\hline 71 & 0.6489 & -0.0145 & 0.5588 & -0.0259 & 0.5716 & -0.0135 & 0.5707 & -0.0166 & 0.3557 & -0.0266 \\
\hline 72 & 0.6391 & -0.0151 & 0.5430 & -0.0284 & 0.5638 & -0.0135 & 0.5611 & -0.0170 & 0.3462 & -0.0266 \\
\hline 73 & 0.6290 & -0.0158 & 0.5262 & -0.0309 & 0.5562 & -0.0135 & 0.5513 & -0.0173 & 0.3370 & -0.0266 \\
\hline 74 & 0.6188 & -0.0163 & 0.5087 & -0.0333 & 0.5487 & -0.0135 & 0.5416 & -0.0177 & 0.3281 & -0.0266 \\
\hline 75 & 0.6083 & -0.0170 & 0.4994 & -0.0358 & 0.5413 & -0.0135 & 0.5318 & -0.0180 & 0.3193 & -0.0266 \\
\hline 76 & 0.5976 & -0.0176 & 0.4716 & -0.0383 & 0.5327 & -0.0159 & 0.5220 & -0.0184 & 0.3109 & -0.0266 \\
\hline 77 & 0.5867 & -0.0182 & 0.4524 & -0.0408 & 0.5221 & -0.0198 & 0.5122 & -0.0187 & 0.3026 & -0.0266 \\
\hline 78 & 0.5757 & -0.0188 & 0.4328 & -0.0433 & 0.5098 & -0.0237 & 0.5025 & -0.0191 & 0.2945 & -0.0266 \\
\hline 79 & 0.5646 & -0.0194 & 0.4130 & -0.0458 & 0.4957 & -0.0275 & 0.4927 & -0.0194 & 0.2867 & -0.0266 \\
\hline 80 & 0.5533 & -0.0200 & 0.3930 & -0.0483 & 0.4802 & -0.0314 & 0.4829 & -0.0198 & 0.2791 & -0.0266 \\
\hline 81 & 0.5419 & -0.0206 & 0.3731 & -0.0508 & 0.4632 & -0.0353 & 0.4732 & -0.0202 & - & - \\
\hline 82 & 0.5304 & -0.0212 & 0.3532 & -0.0533 & 0.4451 & -0.0392 & 0.4635 & -0.0205 & - & - \\
\hline 83 & 0.5189 & -0.0218 & 0.3335 & -0.0558 & 0.4259 & -0.0430 & 0.4538 & -0.0209 & - & - \\
\hline 84 & 0.5072 & -0.0224 & 0.3141 & -0.0582 & 0.4059 & -0.0469 & 0.4442 & -0.0212 & - & - \\
\hline 85 & 0.4956 & -0.0230 & 0.2950 & -0.0607 & 0.3853 & -0.0508 & 0.4346 & -0.0216 & - & - \\
\hline 86 & 0.4839 & -0.0236 & 0.2764 & -0.0632 & 0.3643 & -0.0547 & 0.4251 & -0.0219 & - & - \\
\hline 87 & 0.4722 & -0.0242 & 0.2582 & -0.0657 & 0.3429 & -0.0585 & 0.4156 & -0.0223 & - & - \\
\hline 88 & 0.4605 & -0.0248 & 0.2406 & -0.0682 & 0.3215 & -0.0624 & 0.4062 & -0.0226 & - & - \\
\hline 89 & 0.4487 & -0.0254 & 0.2236 & -0.0707 & 0.3002 & -0.0663 & 0.3968 & -0.0230 & - & - \\
\hline 90 & 0.4371 & -0.0260 & 0.2072 & -0.0732 & 0.2792 & -0.0702 & 0.3876 & -0.0233 & - & - \\
\hline 91 & 0.4254 & -0.0266 & 0.1915 & -0.0757 & 0.2585 & -0.0740 & 0.3784 & -0.0237 & - & - \\
\hline 92 & 0.4138 & -0.0272 & 0.1766 & -0.0781 & 0.2383 & -0.0779 & 0.3693 & -0.0240 & - & - \\
\hline 93 & 0.4023 & -0.0278 & 0.1623 & -0.0806 & 0.2188 & -0.0818 & 0.3603 & -0.0244 & - & - \\
\hline 94 & 0.3909 & -0.0284 & 0.1488 & -0.0831 & 0.2001 & -0.0857 & 0.3513 & -0.0248 & - & - \\
\hline 95 & 0.3795 & -0.0290 & 0.1361 & -0.0856 & 0.1822 & -0.0895 & 0.3425 & -0.0251 & - & - \\
\hline 96 & 0.3683 & -0.0296 & 0.1241 & -0.0881 & 0.1652 & -0.0934 & 0.3338 & -0.0255 & - & - \\
\hline 97 & 0.3572 & -0.0302 & 0.1129 & -0.0906 & 0.1491 & -0.0973 & 0.3252 & -0.0258 & - & - \\
\hline 98 & 0.3461 & -0.0308 & 0.1024 & -0.0931 & 0.1340 & -0.1012 & 0.3167 & -0.0262 & - & - \\
\hline $\mathscr{9 9}$ & 0.3352 & -0.0315 & 0.0926 & -0.0956 & 0.1199 & -0.1050 & 0.3083 & -0.0265 & - & - \\
\hline 100 & 0.3245 & -0.0321 & 0.0835 & -0.0981 & 0.1069 & -0.1089 & 0.3000 & -0.0269 & - & - \\
\hline
\end{tabular}

Notes: The values for $R_{35}$ are taken from MAGT. The values for $R_{k}$ ore computed using the coeficient estimates in lines $1-9$ in table 1 . $D_{k}=R_{k} / R_{k-1}-1$. 
expected to be mostly negative rather than mostly positive, and the frontier estimates are based on trying to force all the estimated residuals to be non-positive rather than non negative. The estimation results are presented in table 4.

The results for the high jump and triple jump are similar to each other. They are also similar to the results for the pooled sample in line 18 in table 1 , although the estimated slowdown rates are somewhat higher for the two field events. The estimated slowdown rates are considerably larger for the pole vault and the long jump, especially after the quadratic takes over at ages 64.1 and 74.0 , respectively.

Sensible results using the quadratic specification could not be obtained for the other four field events-the throwing events. The relationship between $r_{k}$ and $k$ appeared to be linear or close to linear up to about age 80 , and there were not enough observations past age 80 to estimate the quadratic part with even moderate precision. There is, however, a remarkable similarity in results across the four throwing events when the linear specification is used. These results are presented in lines 5-8 in table 4 . The estimates of $\alpha_{2}$ range only from -0.0273 to -0.0281 . When the four events are pooled (line 9), the estimate of $\alpha_{2}$ is -0.0278 . This estimated slowdown rate is larger than the rates for the other four field events except for the pole vault and the long jump at the older ages. This estimated rate for the four throwing events seems relevant up to about age 80 , but it should not be extrapolated beyond this. The data so far tell us little about what happens beyond age 80 .

The frontier estimates for the first four field events and for the four throwing events pooled are presented in lines $10-14$ in table 4 . As was the case for the track and road racing events, the differences between the NLS estimates and the frontier estimates are small, especially regarding the implied derivative values. The largest difference is for the high jump, where the estimate of $k_{3}$ is increased from 51.5 to 62.7 and the estimate of $\alpha_{5}$ is changed from -0.00015 to -0.00030 . Even here, however, the effects on the derivatives are fairly small.

The implied values of $R_{k}$ for the first four field events and for the four throwing events pooled are presented in table 5 . Only values through age 80 are presented for the four throwing events pooled, for reasons discussed above. The estimates in lines 10-14 in table 4 were used for these values, which are the estimates based on the frontier procedure. The values for $R_{35}$ for each event were taken from MAGT.

Comparing tables 3 and 5 , almost all the derivatives are larger in absolute value in table 5 . Men seem to slow down faster in the field events than they do in the track and road racing events. The two exceptions to this are (1) the high jump and triple jump at the older ages, where the slowdown rates are not out of line with the rates for the pooled events in table 3 , and (2) the marathon, where the slowdown rates at the older ages are high relative to the rates for the high jump, triple jump, and the throwing events. These two exceptions pertain only to ages beyond about 80 , however, and it seems clear that for ages below 80 the slowdown rate is greater for the field events than it is for the running events.

\section{Conclusion}

Do the above results have anything to do with economics? As noted in the Introduction, policies on aging should take into account physical deterioration rates. Looking at the numbers in table 3 , I am struck by how small the deterioration rates are. For example, under the assumption that the estimates can be applied to a given individual and using the values of $R_{k}$ for the events 400 meters-half marathon, a man of 85 is only $49 \%$ slower than he was at age $55(1.8007$ versus 1.2102). (Presumably the numbers are similar for women.) Table 3 may thus have something to say about policies on aging. In particular, it may be that societies have been too pessimistic about losses from aging for individuals who stay healthy and fit. Societies may have passed laws dealing with old people under incorrect assumptions. But then again it may be that the numbers in table 3 are only of interest to old runners as they run ever more slowly into the sunset.

\section{REFERENCES}

Aigner, D. J., and S. F. Chu, "On Estimating the Industry Production Function," The American Economic Review S8 (Sept. 1968), 826-839.

Dehn, Michael M., and Robert A. Bruce, "Longitudinal Variation in Maximal Oxygen Intake with Age and Activity," Joumal of Applied Physiology 33 (Dec. 1972), 805-807. 
Greene, William H., "Maximum Likelihood Estimation of Econometric Frontier Functions," Journal of Econometrics 13 (May 1980), 27-56.

Heath, G. W, J. M. Hagberg. Ali A. Ehsani, and J. $O$. Holloszy, "A Physiological Comparison of Young and Older Endurance Athletes," Journal of Applied Physiology 51 (Sept. 1981), 634-640.

Mundle, Peter, Shirley Dietderich, Alan Wood, Don Henry, and Gordon Wallace, Masters Age Records, 1989. , Masters Age Records, 1990. , Masters Age Records for 1990, 1991 edition.

National Masters News, Masters Age-Graded Tables, 1989 edition, Van Nuys, CA.

Poirier, D. J., The Economics of Structural Change with Special Emphasis on Spline Functions (Amsterdam: North-Holland, 1976).

Rogers, Marc A., James M. Hagberg, Wade H. Martin III, Ali A. Eksani, and John O. Holloszy, "Decline in $\mathrm{VO}_{2 \text { max }}$ with Aging in Master Athletes and Sedentary Men," Journal of Applied Physiology 68 (May 1990), 2195-2199.

Schmidt, Peter, "On the Statistical Estimation of Parametric Frontier Production Functions." this Review 53 (May 1976). 238-239. 